\title{
Early Predictors of Acute Pancreatitis Related In-Hospital Mortality: How Practical Are They?
}

\author{
Elham Ahmed Hassan 1*, Abeer Sharaf El-Din Abdel Rehim1, Mohammad Alyamany Kobeisy², \\ Ahmed Mohammed Ashmawy², Zain El-Abdeen Ahmed Sayed², Raed Salah Ameen ${ }^{2}$
}

\author{
${ }^{1}$ Department of Tropical Medicine and Gastroenterology, Faculty of Medicine, Assiut University, Assiut, Egypt \\ ${ }^{2}$ Department of Internal Medicine, Faculty of Medicine, Assiut University, Assiut, Egypt \\ Email: *mam_elham75@yahoo.com, sharafabeer@yahoo.com,yamany1@yahoo.com,dr.ashmawy82@gmail.com, \\ drzain73@yahoo.com, Ramy_salah20011@yahoo.com
}

How to cite this paper: Hassan, E.A., Rehim, A.S.E.-D.A., Kobeisy, M.A., Ashmawy, A.M., Sayed, Z.E.-A.A. and Ameen, R.S. (2018) Early Predictors of Acute Pancreatitis Related In-Hospital Mortality: How Practical Are They? Open Journal of Gastroenterology, 8, 67-78.

https://doi.org/10.4236/ojgas.2018.83007

Received: February 12, 2018

Accepted: March 12, 2018

Published: March 15, 2018

Copyright (๑) 2018 by authors and Scientific Research Publishing Inc. This work is licensed under the Creative Commons Attribution International License (CC BY 4.0).

http://creativecommons.org/licenses/by/4.0/

\begin{abstract}
Background/Purpose: Early assessment of the severity of acute pancreatitis (AP) is a highly challenge for a physicians' practice to improve the management and decrease the mortality. We aimed to determine early prognostic factors for AP related in-hospital mortality. Methods: Upon hospital admission, predictors of AP related in-hospital mortality were prospectively assessed using regression analysis over 129 consecutive AP patients. Predictive abilities of these prognostic factors were compared using the area under receiver operating characteristic curve (AUC). Results: AP related in-hospital mortality was $10.9 \%$. Red cell distribution (RDW), serum creatinine, glucose and albumin were associated with AP mortality. RDW had the highest AUC followed by serum creatinine and albumin (AUC: 914, 95\% CI: 0.797 - 0.975; 0.797, 95\% CI: $0.695-0.878 ; 0.798,95 \%$ CI: $0.677-0.865$ respectively). The cut-off with the best ability to predict in-hospital mortality was 14.2 for RDW. By coupling RDW and serum creatinine, AUC was improved to $0.940,95 \%$ CI: 0.839 - 0.986. Conclusion: RDW, serum creatinine, albumin, and glucose even with borderline level changes may predict AP related in-hospital mortality, where, RDW has the highest prognostic accuracy. Coupling RDW and serum creatinine model significantly improves their predictive accuracy that may aid in further improvement of the quality of care of AP patients.
\end{abstract}

\section{Keywords}

Acute Pancreatitis, In-Hospital Mortality, Red Cell Distribution Width

\section{Introduction}

Acute inflammation of the pancreas (AP) has a wide spectrum of severity. It is 
varied from mild and self-limiting acute pancreatitis (MAP) in approximately $80 \%$ that resolves without serious complications to severe form that carries major morbidity as necrosis or organ failure and increased mortality [1].

The overall mortality of AP is about $10 \%-15 \%$ and can reach up to $42 \%$ in severe AP [2] [3] [4]. Because of nearly $50 \%$ of deaths occur early within the first week, early diagnosis with accurate assessment of the disease severity is a highly challenge in practice [5] [6]. Death from multi-organ failure may occur early within the first 10 days after hospitalization due to massive inflammatory responses or late at the end of the second week from the disease onset that related to infected pancreatic necrosis [5] [6]. Therefore, monitoring AP patients in the first 24 hours of hospital admission is of the great importance that gives a rational for studies to identify those at risk of multi-organ failure to institute an early intervention to decrease mortality. Several prognostic scoring systems have been proposed for that issue; however, it may take longer time for observation i.e. after 48 hours as Ranson's criteria [7], or its use is complex as The Acute Physiology And Chronic Health Evaluation II (APACHE II) scoring system [8]. Whereas, laboratory indexes such as IL-6, CRP, serum lipase and amylase, although, easy feasibility, but their results have been inconsistent and unrelated to the disease severity [9]. Therefore, the presence of sensitive, easy available and inexpensive laboratory markers for predicting the early AP mortality is recommended.

The aim of this study was to assess the clinical and the laboratory data of AP patients upon hospital admission to investigate the early predictors of AP related in-hospital mortality.

\section{Patients and Methods}

\subsection{Study Design}

This was a prospective observational study carried out at Assiut University Hospital (AUH), Egypt, from January 2016 to December 2017. The study was approved by the Ethics Committee of AUH and was conducted in accordance with the previsions of the Declaration of Helsinki. An informed consent was obtained from all the participants before enrollment.

\subsection{Study Population}

This study consecutively included 129 adult patients with AP admitted to Tropical Medicine and Gastroenterology and Internal Medicine Departments, Al-Rajhi Liver Center, Assiut University Hospital, Egypt. AP diagnosis was based on at least 2 of the following Atlanta criteria: 1) typical clinical symptoms; abdominal pain consistent with AP; 2) elevated serum amylase and/or lipase levels greater than 3 times the upper normal limit; 3) characteristic radiological findings by abdominal computerized tomography or ultrasonography.

According to the revised Atlanta classification [6], acute pancreatitis (AP) was categorized into mild acute pancreatitis (MAP with absence of organ failure and 
local/systemic complications.), moderately severe acute pancreatitis (MSAP with transient organ failure/organ failure and/or local or systemic complications that resolved within 48 hours), and severe acute pancreatitis (SAP with persistent single or multiple organ failure $>48$ hours duration). For the purpose of analysis, the MSAP cases with the SAP cases were grouped together [10].

The etiology of AP was either 1) biliary: when imaging [as ultrasonography or computed tomography (CT)], or endoscopic retrograde cholangiopancreatography (ERCP) revealed gallstones in the gallbladder or in the common bile duct. 2) alcohol-induced was diagnosed when alcohol intake before the onset of the symptoms could be established. 3) Other: when attributed to ERCP, hyperlipedemia, trauma, or drugs. 4) Idiopathic or unknown in other cases. Patients with the evidence of chronic pancreatitis, anemia, malignancy, known kidney or liver failure, severe infection within the last month, or organ transplantation were excluded.

\subsection{Methods}

At the time of hospital admission, a thorough medical history and physical examination were taken; for example demographic data, etiology of pancreatitis, organ failure, and severity of AP were noted. Blood samples were also collected for laboratory investigations, and included: complete blood count including white blood cells (WBC), hemoglobin (Hb), platelets (PLT) and red cell distribution width (RDW), liver function tests, kidney function tests including serum creatinine and blood urea nitrogen (BUN), serum sodium, serum calcium, serum potassium, serum glucose (only for non-diabetic patients), C-reactive protein (CRP) and lactate dehydrogenase (LDH), and arterial blood gas analysis. The primary end point was in-hospital mortality.

\subsection{Statistical Analysis}

All statistical analyses were carried out using SPSS for Windows version 16 (SPSS, Chicago, IL, USA) and the MedCalc program. Quantitative data are expressed as mean \pm standard deviation or median and the interquartile range and were compared using Student's t or Mann-Whitney U-tests for normally or abnormally distributed data, respectively. Categorical variables were expressed as percentage and compared using chi-squared $\left(\chi^{2}\right)$ or Fisher's exact probability test. All significant factors on univariate analysis were considered for inclusion in multiple regression analysis to predict AP-related in-hospital mortality. The receiver operating characteristic (ROC) curves were plotted to measure and compare the performance of different parameters to determine death risk and to select the best cut-off point at which sensitivity, specificity, positive (PPV) and negative (NPV) predictive value, positive and negative likelihood ratio $(+\mathrm{LR}$, $-\mathrm{LR}$ ) were calculated. The Kaplan-Meier method was used to estimate the overall survival rates. All tests were two-tailed and statistical significance was assessed at $<0.05$. 


\section{Results}

\subsection{Characteristics of the Studied Patients}

Total 129 patients with AP (70 males and 59 females; mean age $53.6 \pm 10.7)$ were enrolled in the present study. Based on the Atlanta classification, 72 patients (55.8\%) had MAP, and MSAP and SAP were detected in 57 (44.2\%). The etiology of AP was biliary in 89 patients (69\%), idiopathic in 25 patients (19.4\%) and other causes in 15 patients (11.6\%). None of patients were alcoholic. Fourteen patients died during the hospital stay (10.9\%) from: septic and toxic shock (3 cases), multiple organ dysfunction syndrome (6 cases), disseminated intravascular coagulation ( 1 case) and acute renal insufficiency (4 cases). Out of 115 survivors, 25 patients had local pancreatic complications when they were discharged from the hospital, including 12 patients had pancreatic pseudocyst, 11 patients developed necrotizing pancreatitis, and 2 with pancreatic abscess. The mean hospital stay was $10.6 \pm 5.9$ days. Demographic, clinical, and laboratory characteristics of survivors and non-survivors were summarized in Table 1. All the non-survivors had SAP where the levels of serum bilirubin, urea nitrogen, creatinine, blood glucose, and RDW were significantly increased, while the levels of albumin, calcium, and hemoglobin were significantly decreased $(P<0.05)$.

\subsection{Risk Factors Analysis for AP Related In-Hospital Mortality}

To identify the factors that could independently predict AP related in-hospital mortality, multiple regression analysis was applied using the significant variables from the univariate analysis $(P<0.05)$ (Table 1$)$. It was found that increased RDW, serum glucose and creatinine and decreased serum albumin were independent predictors of AP mortality $(P<0.05)$ (Table 2$)$. Moreover, using multiple regression analysis with forward LR method to construct a model with higher accuracy for prediction of AP related in-hospital mortality, a combined use of serum creatinine and RDW offered an accuracy of 92.3\% (Table 3 ).

\subsection{Diagnostic Performance of Parameters for Prediction of AP Related In-Hospital Mortality}

We examined the effectiveness of RDW, serum glucose, creatinine and albumin in prediction of AP related in-hospital mortality using ROC analysis. It was found that the area under curve (AUC) values of these variables were statistically significant to predict AP mortality (Figure 1). RDW had the highest AUC (0.914; 95\% CI 0.797 - 0.975), followed by serum creatinine, albumin and glucose (AUC $=0.797,0.789$ and 0.746 respectively). Moreover, at a cut-off value of RDW $>14.2 \%$, the highest sensitivity (78\%), specificity (96\%), PPV (70.3\%), and NPV (97.3\%) were achieved for prediction of AP related in-hospital mortalityin approximately $77.8 \%$ of the cases (Table 4 ).

Further, we examined the effectiveness of RDW-serum creatinine model in prediction of AP related in-hospital mortality using ROC analysis where AUC was significantly improved $(0.940,95 \%$ CI $0.839-0.986, P<0.001)$ (Figure 2). 
Table 1. Demographic and clinical characteristics of the study patients with acute pancreatitis (survivors and non-survivors).

\begin{tabular}{|c|c|c|c|}
\hline Variables & $\begin{array}{l}\text { Non-survivors } \\
\quad(n=14)\end{array}$ & $\begin{array}{l}\text { Survivors } \\
(n=115)\end{array}$ & $P$ value \\
\hline Age (years; mean $\pm S D$ ) & $63.9 \pm 10.03$ & $43.3 \pm 11.3$ & 0.001 \\
\hline $\operatorname{Sex}(M / F)$ & $8 / 6(57.1 / 42.9)$ & $51 / 64(44.3 / 55.7)$ & 0.449 \\
\hline \multicolumn{4}{|l|}{ Severity of AP } \\
\hline MAP & 0 & $70(60.9 \%)$ & \\
\hline SAP & $14(100 \%)$ & $45(39.1 \%)$ & $<0.001$ \\
\hline Hospital stay (days; mean \pm SD) & $17 \pm 6.9$ & $11.4 \pm 5.3$ & 0.160 \\
\hline $\mathrm{WBC} \operatorname{count}\left(10^{3} / \mu \mathrm{l} ;\right.$ mean $\left.\pm \mathrm{SD}\right)$ & $7.8 \pm 1.3$ & $7.3 \pm 4.2$ & 0.528 \\
\hline Hemoglobin (g/dl; mean \pm SD) & $10.1 \pm 1$ & $13.3 \pm 2.1$ & 0.035 \\
\hline Platelet count $\left(10^{3} / \mu \mathrm{l} ;\right.$ mean \pm SD $)$ & $247.9 \pm 66.2$ & $256.4 \pm 93.4$ & 0.803 \\
\hline Total bilirubin $(\mathrm{mg} / \mathrm{l}$; mean $\pm \mathrm{SD})$ & $4.5 \pm 2.3$ & $1.8 \pm 0.9$ & 0.014 \\
\hline Serum albumin $(\mathrm{mg} / \mathrm{l}$; mean $\pm \mathrm{SD})$ & $28.3 \pm 3.6$ & $34.3 \pm 5.1$ & 0.006 \\
\hline $\begin{array}{l}\text { Aspartate aminotransferase } \\
\text { (U/L; median, range) }\end{array}$ & $38.5(23-224)$ & $26.3(13-411)$ & 0.118 \\
\hline $\begin{array}{l}\text { Alanine aminotransferase } \\
\text { (U/L; median, range) }\end{array}$ & $36.5(32-109)$ & $34.7(7-593)$ & 0.445 \\
\hline Calcium $(\mathrm{mmol} / \mathrm{l}$; mean $\pm \mathrm{SD})$ & $2 \pm 0.4$ & $2.8 \pm 0.3$ & 0.02 \\
\hline Urea (mmol/1; median, range) & $7.1(6-46)$ & $4.9(1.3-32)$ & 0.003 \\
\hline Creatinine ( $\mu \mathrm{mol} / \mathrm{l}$; median, range) & $124(90-696)$ & $102(29-409)$ & 0.009 \\
\hline Serum amylase (U/L; median, range) & $390.7(345-894)$ & $445.3(122-4247)$ & 0.670 \\
\hline Blood sugar (mg/dl; mean \pm SD) & $11.1 \pm 2.1$ & $8.2 \pm 2.2$ & 0.013 \\
\hline RDW (\%; mean \pm SD) & $15.03 \pm 1.3$ & $12.5 \pm 1.4$ & $<0.001$ \\
\hline CRP (mg/l; median, range) & $65.1(55-456)$ & $60(5-425)$ & 0.708 \\
\hline $\begin{array}{l}\text { Lactate dehydrogenase } \\
\text { (U/L; median, range) }\end{array}$ & $281.3(142-752)$ & $272.5(130-675)$ & 0.456 \\
\hline
\end{tabular}

$P$ value $<0.05=$ significant. AP: acute pancreatitis; MAP: mild acute pancreatitis; SAP: severe acute pancreatitis; WBC: white blood cell; RDW: red cell distribution width; CRP: C-reactive protein.

\subsection{Determination of the Survival Analysis}

Kaplan-Meier-estimated survival curves were generated for patients who fell above and below the cut-off values identified by the means of the ROC curves for RDW and serum creatinine constituting this model to predict AP-related in-hospital mortality (Figure 3). These cut-offs clearly differentiated between patients with different survival times; patients who had scores higher than the cut-off value had a significantly shortened survival period compared with patients who had lower scores (long rank, $P=0.013$; Breslow, $P=0.01$ and Tarone-Ware, $P=0.006$ ).

\section{Discussion}

This prospective study demonstrated the early prognostic factors in AP patients and their diagnostic performance to predict mortality. Elaborating reliable 
Table 2. Multiple regression analysis of risk factors affected acute pancreatitis related in-hospital mortality in the studied sample.

\begin{tabular}{ccc}
\hline Variables & Odds ratio & $P$ value \\
\hline Age (years) & $1.4(0.8-2.5)$ & 0.271 \\
Hemoglobin $(\mathrm{g} / \mathrm{dl})$ & $1.7(0.6-5)$ & 0.366 \\
Total bilirubin $(\mathrm{mg} / \mathrm{l})$ & $2.7(0.2-2.9)$ & 0.215 \\
Serum albumin $(\mathrm{mg} / \mathrm{l})$ & $0.7(0.6-.9)$ & 0.007 \\
Calcium $(\mathrm{mmol} / \mathrm{l})$ & $1.7(0.3-11)$ & 0.563 \\
Urea $(\mathrm{mmol} / \mathrm{l})$ & $1.1(0.8-1.5)$ & 0.512 \\
Creatinine $(\mathrm{mmol} / \mathrm{l})$ & $1(0.9-1.03)$ & 0.015 \\
Blood sugar $(\mathrm{mmol} / \mathrm{l})$ & $1.1(1-1.2)$ & 0.017 \\
RDW $(\%)$ & $2.7(1.2-16.1)$ & 0.016 \\
\hline
\end{tabular}

$P$ value $<0.05=$ significant. RDW: red cell distribution width.

Table 3. Diagnostic models for prediction of acute pancreatitis related in-hospital mortality.

\begin{tabular}{|c|c|c|c|c|c|c|c|c|c|c|}
\hline & & \multirow[t]{2}{*}{ B } & \multirow[t]{2}{*}{ S.E. } & \multirow[t]{2}{*}{ Wald } & \multirow[t]{2}{*}{ df } & \multirow[t]{2}{*}{ Sig. } & \multirow{2}{*}{$\begin{array}{l}\text { Exp } \\
\text { (B) }\end{array}$} & \multicolumn{2}{|c|}{$\begin{array}{c}95 \% \text { CI for } \\
\operatorname{EXP}(B)\end{array}$} & \multirow[t]{2}{*}{ Percentage } \\
\hline & & & & & & & & Lower & Upper & \\
\hline \multicolumn{11}{|c|}{ Variables in the Equation for prediction of mortality } \\
\hline \multirow{3}{*}{ Step $1^{\mathrm{a}}$} & Creatinine & 0.009 & 0.003 & 7.132 & 1 & 0.008 & 1.009 & 1.002 & 1.015 & \multirow{4}{*}{91} \\
\hline & & & & & & & & & & \\
\hline & Constant & -3.397 & 0.639 & 28.303 & 1 & $<0.001$ & 0.033 & & & \\
\hline \multirow{3}{*}{ Step $2^{\mathrm{b}}$} & Creatinine & 0.010 & 0.004 & 5.372 & 1 & 0.020 & 1.010 & 1.002 & 1.019 & \\
\hline & RDW & 1.963 & 0.728 & 7.277 & 1 & 0.007 & 7.119 & 1.710 & 29.634 & \multirow[t]{2}{*}{92.3} \\
\hline & Constant & -31.048 & 10.663 & 8.478 & 1 & 0.004 & 0.000 & & & \\
\hline
\end{tabular}

$P$ value $<0.05=$ significant. $\mathrm{RDW}:$ red cell distribution width.

factors and identification of high-risk hospitalized AP patients remain a challenge of increasing suspicions for early decisions of proper management and organ support. In this study, the AP related in-hospital mortality rate of $10.9 \%$ was within the range of the previous estimates $(10 \%-15 \%)$ [3] [4]. However, this lower percentage may be attributed to the early and proper management of gallstones as an etiology of most of AP cases.

We found that all the non-survivors had SAP that was in agreement with earlier studies, where they reported that SAP can lead to a higher risk of systemic complications, pancreatic necrosis, prolonged hospital stay and increased mortality rates of up to $50 \%[11][12]$. 
Table 4. Diagnostic accuracy of prognostic parameters to predict acute pancreatitis related in-hospital mortality with the best predictive cut-offs.

\begin{tabular}{ccccccccc}
\hline & $\begin{array}{c}\text { AUC } \\
95 \% \mathrm{CI}\end{array}$ & $\begin{array}{c}\text { SEN } \\
(\%)\end{array}$ & $\begin{array}{c}\text { SPE } \\
(\%)\end{array}$ & $\begin{array}{c}\text { PPV } \\
(\%)\end{array}$ & $\begin{array}{c}\text { NPV } \\
(\%)\end{array}$ & +LR & -LR & $\begin{array}{c}\text { Accuracy } \\
(\%)\end{array}$ \\
\hline $\begin{array}{c}\text { Serum albumin } \\
(<31 \mathrm{mg} / \mathrm{l})\end{array}$ & $\begin{array}{c}0.789 \\
(0.677-0.865)\end{array}$ & 77.8 & 78.4 & 30.5 & 96.7 & 3.6 & 0.3 & 78.3 \\
$\begin{array}{c}\text { Serum creatinine } \\
(>123 \mu \mathrm{mol} / \mathrm{l})\end{array}$ & $\begin{array}{c}0.797 \\
(0.695-0.878)\end{array}$ & 77.8 & 81.1 & 33.4 & 96.8 & 4.1 & 0.3 & 80.7 \\
$\begin{array}{c}\text { Blood glucose } \\
(>8.8 \text { mmol/1) }\end{array}$ & $\begin{array}{c}0.746 \\
(0.639-0.835) \\
0.914\end{array}$ & 66.7 & 90.5 & 46.1 & 95.7 & 7.1 & 0.4 & 87.9 \\
RDW $(>14.2 \%)$ & $(0.797-0.975)$ & 78 & 96 & 70.3 & 97.3 & 19.2 & 0.2 & 94.1 \\
\hline
\end{tabular}

AUC: area under the curve; SEN: sensitivity; SPE: specificity; PPV: positive predictive value; NPV: negative predictive value; +LR: positive likelihood ratio; -LR: negative likelihood ratio; RDW: red cell distribution width.

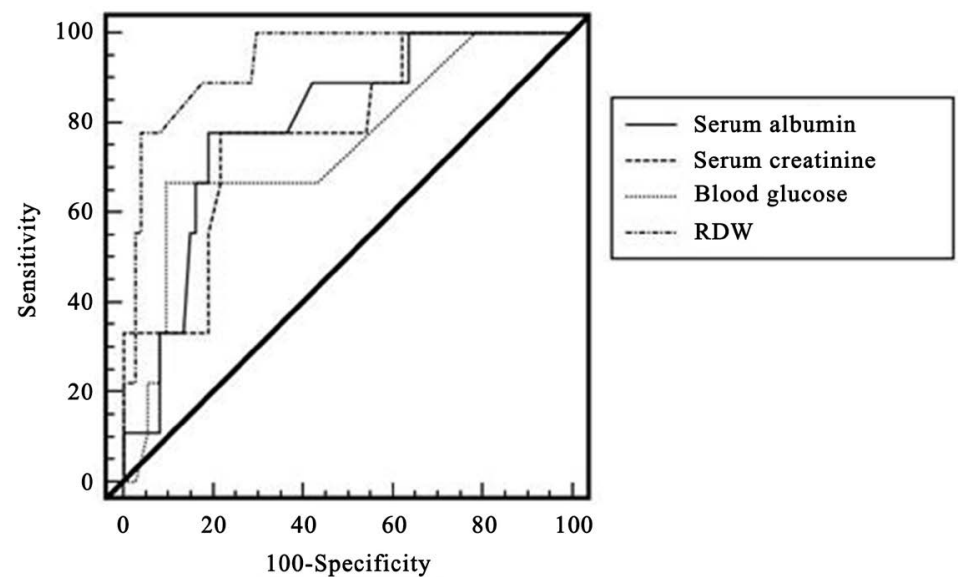

Figure 1. Area under the receiver operating characteristic curve (AUC) of RDW, serum creatinine, albumin and glucose to predict AP-related in-hospital mortality. RDW had the highest AUC in predicting mortality $(\mathrm{AUC}=0.914$ ) followed by serum creatinine, albumin and glucose (AUC $=0.797,0.789$ and 0.746 respectively). AP: Acute pancreatitis; RDW: Red cell distribution width.

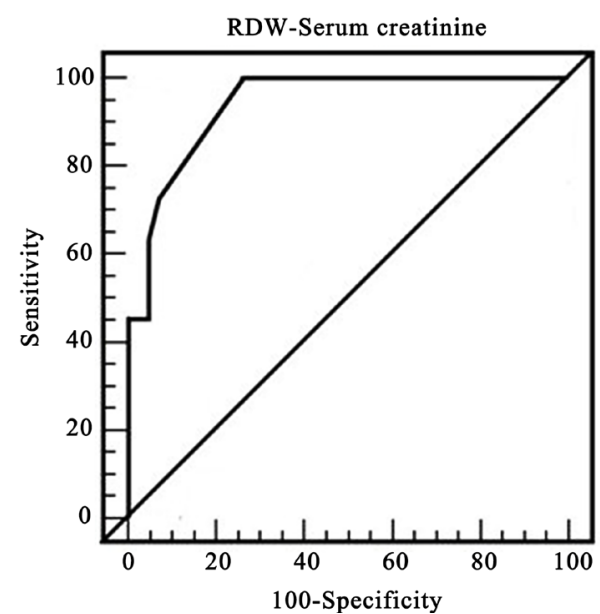

Figure 2. Area under the receiver operating characteristic curve (AUC) of RDW-serum creatinine model to predict AP-related in-hospital mortality, where (AUC $=0.940 ; 95 \%$ 0.839 - 0.986). AP: Acute pancreatitis; RDW: Red cell distribution width. 


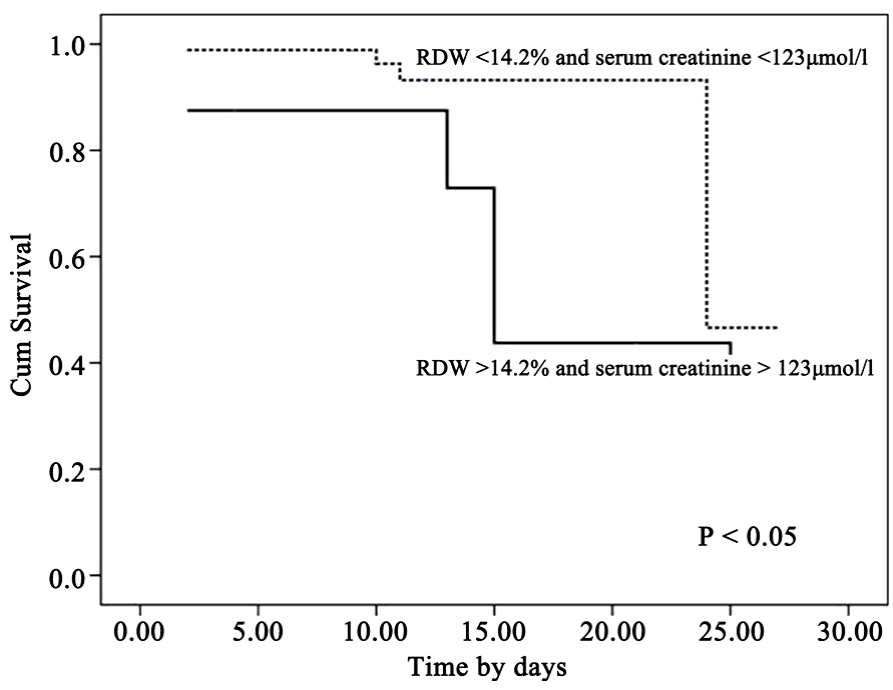

Figure 3. Kaplan-Meier survival curves for RDW-serum creatinine model predicting increased AP-related in-hospital mortality with higher values $(P<0.05)$. AP: Acute pancreatitis; RDW: Red cell distribution width.

This study corroborates increased RDW, serum creatinine, glucose, and lowered albumin levels upon hospital admission were independent risk factors for mortality in AP patients as shown in the previous reports [2] [13] [14]. They found that AP non-survivors had increased levels of RDW and creatinine but decreased levels of albumin compared to survivors. Talamini et al. [14], identified increased serum glucose more than $250 \mathrm{mg} / \mathrm{dl}$ and serum creatinine more than $2 \mathrm{mg} / \mathrm{dl}$ as risk factors for death in AP patients. Thus, RDW, glucose and creatinine may have a risk while albumin may act a protective role in AP patients.

In the present study, the diagnostic accuracy of RDW (AUC $=0.914)$ was significantly higher than the other studied risk factors with 78\% sensitivity, 96\% specificity, $70.3 \% \mathrm{PPV}$ and $97.3 \% \mathrm{NPV}$ at cut-off $>14.2 \%$. This was comparable to the findings of Şenol et al. [15], who reported RDW having AUC of 0.817 with $47.6 \%$ sensitivity, $96.3 \%$ specificity, $79.9 \%$ PPV and $87.6 \%$ NPV at cut off $>14.8$ in predicting fatal outcome in AP patients.

The pathophysiologic mechanisms for the association between the increased RDW levels and AP mortality may be explained as the strong association of some inflammatory cytokines which inhibit erythrocyte maturation and allow larger reticulocytes to enter the circulation [16]. It may be related to inflammation that influences the bone marrow function and iron metabolism and modifies RBC membrane glycoproteins and ion channels, contributing to the change of RBC morphology [17]. In addition, high oxidative stress can also lead to elevated RDW by decreasing red blood cell survival and increasing release of large premature RBCs into the circulation [17].

In consistence with previous studies [18] [19], elevated serum creatinine level at admission was significantly higher in AP patients who died during hospitalization in this study. Additionally, at a cut-off $>123 \mu \mathrm{mol} / \mathrm{l}(1.4 \mathrm{mg} / \mathrm{dl})$ of serum 
creatinine, AUC was 0.782 with $77.8 \%$ sensitivity, $81.1 \%$ specificity and $96.8 \%$ NPV in predicting AP related in-hospital mortality. Renal impairment was an independent predictor for in-hospital mortality in patients with AP, and measurement of creatinine on the first day proved to be a good predictor of mortality [19] [20].

Increased creatinine levels in AP may reflect renal dysfunction because of severe intravascular hypovolemia that may cause reduction in the kidney blood flow [21].

Previous studies reported different cut off values of serum creatinine levels measured at admission time and after 48 hours; Avinash et al. [21], found that serum creatinine $\geq 133 \mu \mathrm{mol} / \mathrm{l}(1.5 \mathrm{mg} / \mathrm{dl})$ on admission was an indicator of the progress towards acute renal failure (ARF). Whereas, Muddana et al. [18], reported that serum creatinine value $>159 \mu \mathrm{mol} / \mathrm{l}(1.8 \mathrm{mg} / \mathrm{dl})$ at 48 hours indicated a higher possibility of the occurrence of pancreatic necrosis (PN), which was a major contributing factor to morbidity and mortality of AP.

On the other hand, high NPV of serum creatinine (96.8\%) in this study agreed with Lankisch et al. [22], who reported that the clinical utility of determining serum creatinine at admission indicates that normal values signify that necrotizing pancreatitis is unlikely, and contrast-enhanced CT is not indicated unless complications occur.

Acute renal failure in AP is caused by the release of vasoactive compounds, enzymes and cytokines from the necrotic pancreatic tissue into the circulation. In addition, activated intravascular coagulation and infection may contribute to the development of ARF in these patients [21].

Serum glucose level upon hospital admission was significantly higher among AP non-survivors in this cohort. This was in agreement with earlier studies that revealed that serum glucose on admission had been considered as a satisfactory predictor of mortality in AP [23] [24]. Our findings revealed that at a cutoff value $>8.8 \mathrm{mmol} / \mathrm{l}(158.4 \mathrm{mg} / \mathrm{dl})$; it had an AUC of $0.746,66.7 \%$ sensitivity, $90.5 \%$ specificity, 46.1\% PPV and 95.7\% NPV in predicting AP-related in-hospital mortality.

Several previous studies [7] [25] demonstrated that at admission, blood glucose level $>11.11 \mathrm{mmol} / \mathrm{l}(200 \mathrm{mg} / \mathrm{dl})$ was added to the early grave Ranson prognostic criteria, and blood glucose $>13.88 \mathrm{mmol} / \mathrm{l}(>250 \mathrm{mg} / \mathrm{dl}$ ) was identified to be a strong predictor of mortality in AP patients [26].

This higher blood glucose levels in the AP non-survivors may be explained to the related probability of damage of the endocrine pancreas, as determined by the extent of the pancreatic necrosis. Similarly to serum creatinine, high NPV of serum glucose $(95.7 \%)$ indicates that its normal values on admission usually signify that necrotizing pancreatitis is unlikely. These findings were matched with previous studies that reported that a blood glucose concentration of $6.9 \mathrm{mmol} / \mathrm{l}$ on admission had a high negative predictive value (92\%) for pancreatic necrosis and also can serve as a predictor for severity [23] [24].

Serum albumin level on admission was significantly lower in deceased AP pa- 
tients in the current results where serum albumin $<31 \mathrm{~g} / \mathrm{d}$ was a good predictor for AP-related in-hospital mortality. This matched with earlier studies that reported that the mortality significantly increased when the serum albumin level was lower than 25 - $30 \mathrm{~g} / \mathrm{l}$ [2] [15] [27]. Albumin is a negative acute phase reactant and its level in the blood decreases with inflammation severity disease prognosis and mortality [28]. Decreased serum albumin levels at the early stage of AP may be attributed to its effusion through the damaged vessel wall into the pancreas and its surrounding tissue that induced by Elastase secreted from pancreas and neutrophils, in addition to the reduction of serum albumin synthesis as a result of damage in liver function in AP [29].

Based on the data in this study, we found that a coupling model of serum creatinine and RDW had a superior accuracy (92.3\%) for prediction of AP related in-hospital mortality than each parameter alone $(\mathrm{AUC}=0.940,95 \% \mathrm{CI}$ $0.839-0.986, P<0.001)$. In addition, patients with higher values than RDW and serum creatinine cut off values had short survival rate as shown by Kaplan-Meier survival analysis.

Thus, this new model may achieve early (within few hours of admission), simple and easily applicable tool to predict adverse outcomes in AP patients before using more sophisticated and expensive techniques. One reason for this superior predictive ability of this coupling model is the inclusion RDW and serum creatinine which are well-known predictors of mortality in AP as shown inprevious studies [13] [15] [19] [20]. This model has yet to be validated prospectively. As this study was a single-center study, further multicenter studies on larger scales are needed to help guide early resuscitation and treatment strategies in acute pancreatitis.

\section{Conclusion}

In conclusion, RDW, serum creatinine, albumin, and glucose even with borderline level changes can predict AP related in-hospital mortality, where, RDW has the highest prognostic accuracy. Coupling RDW and serum creatinine significantly improves their predictive accuracy for AP related in-hospital mortality that may aid in quality of care improvement and in the reduction of short-term mortality. Also, this model may offer a strategy to stratify high-risk patients on hospital admission who may need intensive treatment even without previous episodes of AP, which may require further studies.

\section{Conflict of Interest}

The authors declare that they have no conflict of interest.

\section{References}

[1] Weitz, G., Woitalla, J., Wellhöner, P., Schmidt, K., Büning, J. and Fellermann, K. (2015) Does Etiology of Acute Pancreatitis Matter? A Review of 391 Consecutive Episodes. JOP, 16, 171-175.

[2] Wang, X., Cui, Z., Zhang, J., Li, H., Zhang, D., Miao, B., Cui, Y., Zhao, E., Li, Z. and 
Cui, N. (2010) Early Predictive Factors of in Hospital Mortality in Patients with Severe Acute Pancreatitis. Pancreas, 39, 114-115.

https://doi.org/10.1097/MPA.0b013e3181b65dd5

[3] Dambrauskas, Z., Giese, N., Gulbinas, A., Giese, T., Berberat, P.O., Pundzius, J., Barauskas, G. and Friess, H. (2010) Different Profiles of Cytokine Expression during Mild and Severe Acute Pancreatitis. World Journal of Gastroenterology, 16, 1845-1853. https://doi.org/10.3748/wjg.v16.i15.1845

[4] Abu-Zidan, F.M., Bonham, M.J. and Windsor, J.A. (2000) Severity of Acute Pancreatitis: A Multivariate Analysis of Oxidative Stress Markers and Modified Glasgow Criteria. British Journal of Surgery, 87, 1019-1023. https://doi.org/10.1046/j.1365-2168.2000.01464.X

[5] Bhatia, M., Wong, F.L., Cao, Y., Lau, H.Y., Huang, J., Puneet, P. and Chevali, L. (2005) Pathophysiology of Acute Pancreatitis. Pancreatology, 5, 132-144.

https://doi.org/10.1159/000085265

[6] McKay, C.J. and Imrie, C.W. (2004) The Continuing Challenge of Early Mortality in Acute Pancreatitis. British Journal of Surgery, 91, 1243-1244.

https://doi.org/10.1002/bjs.4750

[7] Ranson, J.H., Rifkind, K.M., Roses, D.F., Fink, S.D., Eng, K. and Spencer, F.C. (1974) Prognostic Signs and the Role of Operative Management in Acute Pancreatitis. Surgery, Gynecology \& Obstetrics, 139, 69-81.

[8] Knaus, W.A., Draper, E.A., Wagner, D.P. and Zimmerman, J.E. (1985) APACHE II: A Severity of Disease Classification System. Critical Care Medicine, 13, 818-829. https://doi.org/10.1097/00003246-198510000-00009

[9] Fisic, E., Poropat, G., Bilic-Zulle, L., Licul, V., Milic, S. and Stimac, D. (2013) The Role of IL-6, 8, and 10, sTNFr, CRP, and Pancreatic Elastase in the Prediction of Systemic Complications in Patients with Acute Pancreatitis. Gastroenterology Research and Practice, Article ID: 282645. https://doi.org/10.1155/2013/282645

[10] Banks, P.A., Bollen, T.L., Dervenis, C., Gooszen, H.G., Johnson, C.D., Sarr, M.G., Tsiotos, G.G. and Vege, S.S. (2013) Classification of Acute Pancreatitis-2012: Revision of the Atlanta Classification and Definitions by International Consensus. Gut, 62, 102-111. https://doi.org/10.1136/gutjnl-2012-302779

[11] Forsmark, C.E., Vege, S.S. and Wilcox, C.M. (2017) Acute Pancreatitis. The New England Journal of Medicine, 376, 598-599.

[12] Bakker, O.J., Issa, Y., van Santvoort, H.C., Besselink, M.G., Schepers, N.J., Bruno, M.J., Boermeester, M.A. and Gooszen, H.G. (2014) Treatment Options for Acute Pancreatitis. Nature Reviews Gastroenterology \& Hepatology, 11, 462-469. https://doi.org/10.1038/nrgastro.2014.39

[13] Moharamzadeh, P., Nia, K.S., Somil, M., Pouraghaei, M., Fadaeihaghi, A. and Rahmani, F. (2018) Red Blood Cell Distribution Width: A Determinant of Hospital Mortality in Pancreatitis. Journal of Emergency Practice and Trauma, 4, 34-38. https://doi.org/10.15171/jept.2017.26

[14] Talamini, G., Bassi, C., Falconi, M., Sartori, N., Frulloni, L., Di Francesco, V., Vesentini, S., Pederzoli, P. and Cavallini, G. (1996) Risk of Death from Acute Pancreatitis. International Journal of Pancreatology, 19, 15-24. https://doi.org/10.1007/BF02788371

[15] Şenol, K., Saylam, B., Kocaay, F. and Tez, M. (2013) Red Cell Distribution Width as a Predictor of Mortality in Acute Pancreatitis. American Journal of Emergency Medicine, 31, 687-689. https://doi.org/10.1016/j.ajem.2012.12.015

[16] Ku, N.S., Kim, H.W., Oh, H.J., Kim, Y.C., Kim, M.H., Song, J.E., Oh, D.H., Ahn, 
J.Y., Kim, S.B., Jeong, S.J., Han, S.H., Kim, C.O., Song, Y.G., Kim, J.M. and Choi, J.Y. (2012) Red Blood Cell Distribution Width Is an Independent Predictor of Mortality in Patients with Gram-Negative Bacteremia. Shock, 38, 123-127. https://doi.org/10.1097/SHK.0b013e31825e2a85

[17] Song, C.S., Park, D.I., Yoon, M.Y., Seok, H.S., Park, J.H., Kim, H.J., Cho, Y.K., Sohn, C.I., Jeon, W.K. and Kim, B.I. (2012) Association between Red Cell Distribution Width and Disease Activity in Patients with Inflammatory Bowel Disease. Digestive Diseases and Sciences, 57, 1033-1038. https://doi.org/10.1007/s10620-011-1978-2

[18] Muddana, V., Whitcomb, D.C., Khalid, A., Slivka, A. and Papachristou, G.I. (2009) Elevated Serum Creatinine as a Marker of Pancreatic Necrosis in Acute Pancreatitis. The American Journal of Gastroenterology, 104, 164-170. https://doi.org/10.1038/ajg.2008.66

[19] Wu, B.U., Johannes, R.S., Sun, X., Conwell, D.L. and Banks, P.A. (2009) Early Changes in Blood Urea Nitrogen Predict Mortality in Acute Pancreatitis. Gastroenterology, 137, 129-135. https://doi.org/10.1053/j.gastro.2009.03.056

[20] Lipinski, M., Rydzewski, A. and Rydzewska, G. (2013) Early Changes in Serum Creatinine Level and Estimated Glomerular Filtration Rate Predict Pancreatic Necrosis and Mortality in Acute Pancreatitis: Creatinine and eGFR in Acute Pancreatitis. Pancreatology, 13, 207-211. https://doi.org/10.1016/j.pan.2013.02.002

[21] Avinash, B., Kalyan, N., Lakshmi, A.Y., Padmanabhan, S. and Siva Kumar, V. (2005) Acute Renal Failure in Acute Pancreatitis-Role of Pancreatic Computed Tomograph.y Severity Index (CTSI). Indian Journal of Nephrology, 15, 14-16.

[22] Lankisch, P.G., Weber-Dany, B., Maisonneuve, P. and Lowenfels, A.B. (2010) High Serum Creatinine in Acute Pancreatitis: A Marker for Pancreatic Necrosis? The American Journal of Gastroenterology, 105, 1196-1200. https://doi.org/10.1038/ajg.2009.688

[23] Lankisch, P.G., Blum, T., Bruns, A., Dröge, M., Brinkmann, G., Struckmann, K., Nauck, M., Maisonneuve, P. and Lowenfels, A.B. (2001) Has Blood Glucose Level Measured on Admission to Hospital in a Patient with Acute Pancreatitis Any Prognostic Value? Pancreatology, 1, 224-229. https://doi.org/10.1159/000055815

[24] Rajaratnam, S.G. and Martin, I.G. (2006) Admission Serum Glucose Level: An Accurate Predictor of Outcome in Gallstone Pancreatitis. Pancreas, 33, 27-30. https://doi.org/10.1097/01.mpa.0000222315.36490.9b

[25] Ranson, J.H.C., Rifkind, K.M. and Turner, J.W. (1976) Prognostic Signs and Nonoperative Peritoneal Lavage in Acute Pancreatitis. Surgery, Gynecology \& Obstetrics, 143, 209-219.

[26] Blum, T., Maisonneuve, P., Lowenfels, A.B. and Lankisch, P.G. (2001) Fatalotcome in Acute Pancreatitis: Its Occurance and Early Prediction, Pancreatology, 1, 237-241. https://doi.org/10.1159/000055817

[27] Triester, S.L. and Kowdley, K.V. (2002) Prognostic Factors in Acute Pancreatitis. Journal of Clinical Gastroenterology, 34, 167-176. https://doi.org/10.1097/00004836-200202000-00014

[28] Goh, S.L., De Silva, R.P., Dhital, K. and Gett, R.M. (2015) Is Low Serum Albumin Associated with Postoperative Complications in Patients Undergoing Oesophagectomy for Oesophageal Malignancies? Interactive CardioVascular and Thoracic Surgery, 20, 107-113. https://doi.org/10.1093/icvts/ivu324

[29] Li, S., Zhang, Y., Li, M., Xie, C. and Wu, H. (2017) Serum Albumin, a Good Indicator of Persistent Organ Failure in Acute Pancreatitis. BMC Gastroenterology, 17, 59. https://doi.org/10.1186/s12876-017-0615-8 